\title{
2018 Audited schedule of changes in net assets
}

\section{BKD}

See end of article for authors' affiliations.

The table below summarizes the association's financial status as of December 31, 2018. For a more complete audit report and related information, see the Audited Financial Statements 2001-2018

(members only). This report includes balance sheets, fund status reports, budgeted and actual revenues and expenditures, and a schedule of investments. Members may obtain a copy of the audit report from MLA headquarters.

Table 1 Medical Library Association schedule of changes in net assets by fund year ended December 31, 2018

\begin{tabular}{|c|c|c|c|c|c|c|}
\hline & $\begin{array}{c}\text { Net assets } \\
\text { January 1, } \\
2018\end{array}$ & $\begin{array}{c}\text { Contributions } \\
\text { and other } \\
\text { revenue }\end{array}$ & $\begin{array}{l}\text { Invest- } \\
\text { ment } \\
\text { return }\end{array}$ & $\begin{array}{l}\text { Net assets } \\
\text { released } \\
\text { from } \\
\text { restrictions }\end{array}$ & Expenses & $\begin{array}{c}\text { Net assets } \\
\text { December } \\
31,2018\end{array}$ \\
\hline \multicolumn{7}{|l|}{$\begin{array}{l}\text { Net assets without donor } \\
\text { restrictions }\end{array}$} \\
\hline General operating & $(\$ 166,924)$ & $\$ 2,993,293$ & - & - & $(\$ 2,977,040)$ & $(\$ 150,671)$ \\
\hline \multicolumn{7}{|l|}{ Other funds: } \\
\hline $\begin{array}{l}\text { Association } \\
\text { stabilization }\end{array}$ & $\$ 1,743,434$ & - & $(\$ 54,674)$ & - & - & $\$ 1,688,760$ \\
\hline Capital equipment & $\$ 2,228$ & - & - & - & - & $\$ 2,228$ \\
\hline Special purpose & - & - & - & $\$ 96,883$ & $(\$ 96,883)$ & - \\
\hline Sections & $\$ 289,573$ & $\$ 48,612$ & - & - & $(\$ 60,972)$ & $\$ 277,213$ \\
\hline $\begin{array}{l}\text { Total net assets without } \\
\text { donor restrictions }\end{array}$ & $\$ 2,035,235$ & $\$ 48,612$ & $(\$ 54,674)$ & $\$ 96,883$ & $(\$ 157,855)$ & $\$ 1,968,201$ \\
\hline \multicolumn{7}{|l|}{$\begin{array}{l}\text { Net assets with donor } \\
\text { restrictions }\end{array}$} \\
\hline $\begin{array}{l}\text { Ysabel Bertolucci MLA } \\
\text { Annual Meeting Grant } \\
\text { Endowment }\end{array}$ & $\$ 33,506$ & $\$ 500$ & $(\$ 1,237)$ & (\$995) & - & $\$ 31,774$ \\
\hline $\begin{array}{l}\text { Estelle Brodman } \\
\text { Award for the } \\
\text { Academic Medical } \\
\text { Librarian of the Year } \\
\text { Endowment }\end{array}$ & $\$ 74,937$ & - & $(\$ 1,232)$ & $(\$ 500)$ & - & $\$ 73,205$ \\
\hline $\begin{array}{l}\text { Naomi C. Broering } \\
\text { Hispanic Heritage } \\
\text { Grant Endowment }\end{array}$ & $\$ 29,759$ & $\$ 50$ & $(\$ 1,066)$ & $(\$ 1,000)$ & - & $\$ 27,743$ \\
\hline $\begin{array}{l}\text { Lois Ann Colaianni } \\
\text { Award for Excellence } \\
\text { and Achievement in } \\
\text { Hospital Librarianship } \\
\text { Endowment }\end{array}$ & $\$ 26,960$ & $\$ 1,000$ & $(\$ 642)$ & $(\$ 500)$ & - & $\$ 26,818$ \\
\hline
\end{tabular}


DOI: dx.doi.org/10.5195 jmla.2019.821

Table 1 Medical Library Association schedule of changes in net assets by fund year ended December 31, 2018 (continued)

\begin{tabular}{|c|c|c|c|c|c|c|}
\hline & $\begin{array}{c}\text { Net assets } \\
\text { January 1, } \\
2018\end{array}$ & $\begin{array}{c}\text { Contributions } \\
\text { and other } \\
\text { revenue }\end{array}$ & $\begin{array}{l}\text { Invest- } \\
\text { ment } \\
\text { return }\end{array}$ & $\begin{array}{l}\text { Net assets } \\
\text { released } \\
\text { from } \\
\text { restrictions }\end{array}$ & Expenses & $\begin{array}{c}\text { Net assets } \\
\text { December } \\
31,2018\end{array}$ \\
\hline $\begin{array}{l}\text { Consumer Health } \\
\text { Librarian of the Year } \\
\text { Award Endowment }\end{array}$ & $\$ 27,975$ & $\$ 5$ & $(\$ 1,082)$ & $(\$ 1,000)$ & - & $\$ 25,898$ \\
\hline $\begin{array}{l}\text { Cunningham Memorial } \\
\text { International } \\
\text { Fellowship Endowment }\end{array}$ & $\$ 166,684$ & - & $(\$ 5,140)$ & $(\$ 8,222)$ & - & $\$ 153,322$ \\
\hline $\begin{array}{l}\text { Louise Darling Medal } \\
\text { for Distinguished } \\
\text { Achievement in } \\
\text { Collection } \\
\text { Development in the } \\
\text { Health Sciences } \\
\text { Endowment }\end{array}$ & $\$ 83,860$ & - & $(\$ 1,510)$ & - & - & $\$ 82,350$ \\
\hline $\begin{array}{l}\text { Janet Doe Lectureship } \\
\text { Endowment }\end{array}$ & $\$ 58,613$ & $\$ 200$ & $(\$ 1,101)$ & (\$798) & - & $\$ 56,914$ \\
\hline $\begin{array}{l}\text { Carla J. Funk } \\
\text { Governmental } \\
\text { Relations Award } \\
\text { Endowment }\end{array}$ & $\$ 20,621$ & $\$ 450$ & (\$687) & $(\$ 500)$ & - & $\$ 19,884$ \\
\hline $\begin{array}{l}\text { Eugene Garfield } \\
\text { Research Fellowship } \\
\text { Endowment }\end{array}$ & $\$ 137,299$ & - & $(\$ 5,224)$ & - & - & $\$ 132,075$ \\
\hline $\begin{array}{l}\text { T. Mark Hodges } \\
\text { International Service } \\
\text { Award Endowment }\end{array}$ & $\$ 4,759$ & $\$ 100$ & (\$203) & - & - & $\$ 4,656$ \\
\hline $\begin{array}{l}\text { Hospital Libraries } \\
\text { Section/MLA } \\
\text { Professional } \\
\text { Development Grant } \\
\text { Endowment }\end{array}$ & $\$ 49,744$ & $\$ 100$ & $(\$ 1,164)$ & $(\$ 450)$ & - & $\$ 48,230$ \\
\hline $\begin{array}{l}\text { David A. Kronick } \\
\text { Traveling Fellowship } \\
\text { Endowment }\end{array}$ & $\$ 17,562$ & $\$ 5,500$ & $(\$ 1,139)$ & $(\$ 2,000)$ & - & $\$ 19,923$ \\
\hline $\begin{array}{l}\text { Joseph Leiter } \\
\text { NLM/MLA } \\
\text { Lectureship } \\
\text { Endowment }\end{array}$ & $\$ 79,169$ & $\$ 1,000$ & $(\$ 1,736)$ & - & - & $\$ 78,433$ \\
\hline $\begin{array}{l}\text { Librarians without } \\
\text { Borders® Ursula } \\
\text { Poland International } \\
\text { Scholarship } \\
\text { Endowment }\end{array}$ & $\$ 28,685$ & $\$ 500$ & (\$953) & $(\$ 1,000)$ & - & $\$ 27,232$ \\
\hline $\begin{array}{l}\text { Donald A. B. Lindberg } \\
\text { Research Fellowship } \\
\text { Endowment }\end{array}$ & $\$ 318,744$ & $\$ 2,500$ & $(\$ 9,105)$ & $(\$ 10,000)$ & - & $\$ 302,139$ \\
\hline
\end{tabular}


Table 1 Medical Library Association schedule of changes in net assets by fund year ended December 31, 2018 (continued)

\begin{tabular}{|c|c|c|c|c|c|c|}
\hline & $\begin{array}{c}\text { Net assets } \\
\text { January 1, } \\
2018\end{array}$ & $\begin{array}{l}\text { Contributions } \\
\text { and other } \\
\text { revenue }\end{array}$ & $\begin{array}{l}\text { Invest- } \\
\text { ment } \\
\text { return }\end{array}$ & $\begin{array}{l}\text { Net assets } \\
\text { released } \\
\text { from } \\
\text { restrictions }\end{array}$ & Expenses & $\begin{array}{l}\text { Net assets } \\
\text { December } \\
31,2018\end{array}$ \\
\hline $\begin{array}{l}\text { Majors/MLA Chapter } \\
\text { Project of the Year } \\
\text { Endowment }\end{array}$ & $\$ 19,563$ & - & $(\$ 480)$ & $(\$ 500)$ & - & $\$ 18,583$ \\
\hline $\begin{array}{l}\text { Lucretia W. McClure } \\
\text { MLA Excellence in } \\
\text { Education Award } \\
\text { Endowment }\end{array}$ & $\$ 54,967$ & $\$ 725$ & $(\$ 1,536)$ & $(\$ 500)$ & - & $\$ 53,656$ \\
\hline $\begin{array}{l}\text { John P. McGovern } \\
\text { Award Lectureship } \\
\text { Endowment }\end{array}$ & $\$ 131,278$ & $\$ 500$ & $(\$ 4,827)$ & - & - & $\$ 126,951$ \\
\hline $\begin{array}{l}\text { MLA Disaster Relief } \\
\text { Fund }\end{array}$ & $\$ 6,354$ & - & - & - & - & $\$ 6,354$ \\
\hline $\begin{array}{l}\text { Scholarship } \\
\text { Endowment }\end{array}$ & $\$ 264,817$ & $\$ 15,208$ & $(\$ 12,650)$ & $(\$ 13,460)$ & - & $\$ 253,915$ \\
\hline $\begin{array}{l}\text { Section Project of the } \\
\text { Year Award } \\
\text { Endowment }\end{array}$ & $(\$ 142)$ & - & - & (\$500) & - & $(\$ 642)$ \\
\hline $\begin{array}{l}\text { Shaping Our Future } \\
\text { Endowment }\end{array}$ & $\$ 71,492$ & $\$ 600$ & $(\$ 2,172)$ & - & - & $\$ 69,920$ \\
\hline $\begin{array}{l}\text { Special } \\
\text { Purpose/Librarians } \\
\text { without Borders }{ }^{\circledR}\end{array}$ & $\$ 59,039$ & $\$ 135,000$ & - & $(\$ 54,958)$ & - & $\$ 139,081$ \\
\hline $\begin{array}{l}\text { Special } \\
\text { Purpose/MLA/NLM } \\
\text { Spectrum Scholarships }\end{array}$ & $\$ 26,000$ & - & - & - & - & $\$ 26,000$ \\
\hline $\begin{array}{r}\text { Total net assets with } \\
\text { donor restrictions }\end{array}$ & $\$ 1,792,245$ & $\$ 163,938$ & $(\$ 54,886)$ & $(\$ 96,883)$ & - & $\$ 1,804,414$ \\
\hline Total all net assets & $\$ 3,660,556$ & $\$ 3,205,843$ & $(\$ 109,560)$ & - & $(\$ 3,134,895)$ & $3,621,944$ \\
\hline
\end{tabular}

\section{AUTHORS' AFFILIATIONS}

BKD, CPAs and Advisors, on behalf of the Medical Library Association, kelly.weaver@mci-group.com, Chicago, IL 